\title{
Dinamika Amonium dan Nitrat Lahan Sawah Latosol pada Budidaya Konvensional Padi Lokal dan Hibrida di Subak Jatiluwih
}

\author{
GITA YUNI PERMATASARI, ANAK AGUNG ISTRI KESUMADEWI ${ }^{*}$, DAN \\ ANAK AGUNG NGURAH GEDE SUWASTIKA
}

\author{
Program Studi Agroekoteknologi, Fakultas Pertanian, Universitas Udayana \\ Jl. PB. Sudirman Denpasar 80231 Bali Indonesia \\ ${ }^{*}$ E-mail: aai-kesumadewi@live.com
}

\begin{abstract}
Ammonium Dynamics and Latosol Wetland Nitrates in Conventional Cultivation of Local and Hybrid Rice in Jatiluwih Subak. Plants absorb nitrogen in the form of ammonium $\left(\mathrm{NH}_{4}^{+}\right)$and nitrate $\left(\mathrm{NO}_{3}{ }^{-}\right)$. Each sample was analyzed for its ammonium and nitrate levels using macro Kjeldahl method. The results showed that the concentration of ammonium and nitrate in soil of the two rice fields were similar. The ions contents were as following: nitrate $(2,67 \%)$ and ammonium $(2,67 \%)$ in local rice, while those in hybrid rice fields were amounted of $1,48 \%$ and $4,59 \%$ respectivelly. The concentration of ammonium and nitrate on $21 \mathrm{DAC}$ in soil samples remained low and rose at $28 \mathrm{DAC}$, then decreased at 56 DAC. It means that the times of fertilizing always done by the farmers were not appropriate.The content of ammonium and nitrate in water phase much lower than that in soils for both types of rice plants. The highest concentration of ammonium in local rice fields was $0,093 \%$ at the time of tillage and the lowest $0 \%$ on $21 \mathrm{DAC}$, while the highest nitrate concentrations in local rice water was $0,37 \%$ at 70 DAC and the lowest was $0 \%$ at of 21 DAC. The highest ammonium concentrations in hybrid rice $0,33 \%$ at 14 DAC, and the lowest $0 \%$ at $42 \mathrm{HST}$, while the highest nitrate content $0,47 \%$ at $42 \mathrm{DAC}$ and the lowest $0 \%$ at the time of tillage. The fertilizing times recommended based on the findings of this reaserch is at 10-15 DAC for both rice types and another subsquent fertilization on 60-65 DAC for local rice and 40-45 DAC in hybrid rice.
\end{abstract}

Keywords: ammonium and nitrate dynamics, rice field

\section{PENDAHULUAN}

Padi (Oryza sativa L) merupakan tanaman pangan utama di Asia, termasuk di Indonesia. Sebagian besar tanaman padi sawah di Indonesia dibudidayakan secara konvensional. Balai Penelitian Tanah
(2011) menyatakan, bahwa sistem budidaya konvensional didominasi oleh penggunaan pupuk dan pestisida kimia. Jenis pupuk yang paling banyak digunakan dalam budidaya padi sawah adalah urea atau sumber nitrogen $(\mathrm{N})$ lainnya. Nitrogen 
GITA YUNI PERMATASARI. et al. Dinamika Amonium dan Nitrat Lahan Sawah Latosol...

dapat diserap oleh tanaman dalam bentuk kation amonium $\left(\mathrm{NH}_{4}^{+}\right)$dan anion nitrat $\left(\mathrm{NO}_{3}{ }^{-}\right)$. Amonium terbentuk melalui proses amonifikasi bahan organik atau hidrolisis pupuk $\mathrm{N}$, sedangkan nitrat terbentuk dari proses nitrifikasi amonium. Oleh karena itu, nitrifikasi sangat menentukan ketersediaan ion-ion $\mathrm{N}$ yang dapat digunakan langsung oleh tanaman. (Suwastika dkk, 2018).

Pemberian $\mathrm{N}$ secara berkelanjutan selalu dibutuhkan pada setiap musim karena kadar $\mathrm{N}$ pada tanah padi sawah umumnya tergolong rendah. Selain rendah, N di dalam tanah mempunyai sifat yang dinamis (mudah berubah dari satu bentuk ke bentuk lain seperti $\mathrm{NH}_{4}{ }^{+}$menjadi $\mathrm{NO}_{3}{ }^{-}, \mathrm{NO}, \mathrm{N}_{2} \mathrm{O}$ dan $\mathrm{N}_{2}$ ) dan mudah hilang tercuci bersama air drainase. Menurut Patti et al., 2013 kehilangan nitrogen yang demikian tinggi tersebut menyebabkan hanya $19-47 \%$ saja yang diserap tanaman, sedangkan penyerapan pupuk $\mathrm{N}$ yang diberikan ke tanaman hanyalah sekitar 40-50\%.

Tanaman padi hibrida umumnya membutuhkan $100 \mathrm{~kg} \quad \mathrm{~N} / \mathrm{ha}$ untuk pertumbuhan. Kebutuhan $\mathrm{N}$ pada tanaman lokal biasanya lebih rendah dibandingkan tanaman hibrida. Haryatie (2013) menemukan bahwa padi hibrida Arize memerlukan N 25\% lebih banyak dibandingkan padi lokal Barito. Ladiyani, dkk. (2013) menyatakan bahwa kebutuhan urea padi hibrida 2 kali lipat dari padi inhibrida.

Tanaman padi sawah yang dibudidayakan di Tabanan terutama di Desa Jatiluwih adalah jenis Ciherang yang digilirkan dengan padi lokal (padi Cicih). Perbedaan mendasar kedua jenis padi tersebut menurut petani lokal adalah umur tanaman dan produksi. Padi lokal berumur lebih panjang (126 hari), sedangkan padi hibrida 110 hari. Produksi padi Cicih biasanya lebih rendah dibandingkan dengan padi Ciherang tetapi padi lokal lebih tahan terhadap serangan OPT. Petani lokal umumnya menggunakan dosis pupuk urea yang sama yaitu $75 \mathrm{~kg}$ N/ha yang ditambahkan sebesar $50 \mathrm{~kg} \mathrm{~N} / \mathrm{ha}$ pada saat tanaman berumur 20 hari dan pemupukan kedua sebesar $25 \mathrm{~kg} \mathrm{~N} / \mathrm{ha}$ pada umur 50 hari. Pemberian pupuk tersebut memiliki dosis yang lebih rendah jika dibandingan dengan dosis pupuk yang dianjurkan. Penelitian ini dilakukan untuk mengamati dinamika amonium dan nitrat pada tanah sawah yang ditanami padi lokal dan hibrida di subak Jatiluwih untuk mengetahui waktu penurunan unsur hara guna mengevaluasi waktu penambahan pupuk yang tepat bagi petani setempat. 


\section{BAHAN DAN METODE}

Penelitian dilaksanakan pada bulan Juli 2018 sampai dengan Maret 2019, terhitung sejak persiapan sampai dengan akhir pelaksanaan penelitian. Lokasi pengambilan sampel penelitian adalah di Subak Jatiluwih yang terletak di Tempek Umodewi, Desa Jatiluwih, Kabupaten Tabanan sedangkan analisis sampel penelitian dilakukan di Laboratorium Ilmu Tanah dan Lingkungan, Fakultas Pertanian Universitas Udayana.

Bahan yang digunakan dalam penelitian ini adalah sampel tanah dan air yang diambil dari lahan sawah konvensional di Subak Jatiluwih, serta bahan-bahan kimia yang digunakan dalam analisis kadar nitrat, amonium, pH tanah dan kadar air. Alat-alat yang digunakan dalam penelitian ini adalah alat tulis kantor, kamera, kertas label, alat tulis, botol plastik, kantong plastik, kaleng susu yang telah diberi lubang pada kedua sisi atas dan bawah, pH meter, spektrofotometer, alat-alat gelas, dan oven.

Penelitian ini adalah penelitian eksploratif untuk mengevaluasi sistem budidaya padi sawah lokal dan hibrida yang dilakukan secara konvensional oleh para petani di subak Jatiluwih. Evaluasi dilakukan terhadap hubungan antara faktor pembeda dengan dinamika amonium dan nitrat, yaitu jenis tanaman padi yang dibudidayakan dan selang waktu setelah aplikasi pupuk $\mathrm{N}$ dengan dinamika amonium dan nitrat. Faktor jenis tanaman padi yang akan dievaluasi adalah jenis padi lokal (padi cicih) dan padi hibrida (varietas Ciheurang) yang masing-masing ditanam oleh petani lokal pada petakan sawah yang berbeda.

Pelaksanaan penelitian diawali dengan survei lapang untuk menentukan lokasi penelitian di Subak Jatiluwih. Lokasi petakan sampel ditentukan secara purposif pada lahan yang selalu dikelola secara konvensional di Subak Jatiluwih. Ditentukan lokasi sampling pada 6 petakan yang memiliki sifat-sifat tanah dan sejarah penggunaan lahan yang relatif sama. Setiap 3 petakan ditanami padi lokal (cicih) dan 3 petakan ditanami padi hibrida (Ciheurang), pada masing-masing petakan diberi kode sesuai dengan jenis tanaman yang ditanam dan masing-masing ulangannya. Selanjutnya, pada masing-masing petakan ditentukan 5 titik sampel yang juga ditandai kemudian dikompositkan menjadi 1 sampel. Prosedur pengambilan sampel tanah dan air dilakukan sesuai berikut.

(1) Pada titik sampel dibenamkan sedalam $30 \mathrm{~cm}$ kaleng susu yang telah diberi lubang pada kedua sisi atas dan 
GITA YUNI PERMATASARI. et al. Dinamika Amonium dan Nitrat Lahan Sawah Latosol...

bawah. (2) Pengambilan sampel air dilakukan pada kaleng yang telah dibenamkan dengan menggunakan spite, kemudian dimasukkan ke dalam botol plastik; (3) Pengambilan sampel tanah dilakukan pada kedalaman $30 \mathrm{~cm}$, kemudian dimasukkan ke dalam kantong plastik; (4) Pengambilan sampel tanah dilakukan sejak pengolaan tanah hingga panen terutama pada waktu $0,7,14$ hari dan selanjutnya akan dilaksanakan tiap 2 minggu, sedangkan pengambilan sampel air dilakukan sepanjang masih ada air atau masih tergenang selama periode tanam.

Pengukuran kadar $\mathrm{N}$-ammonium dan $\mathrm{N}$-nitrat diukur dengan menggunakan metode makro Kjeldahl (Puslittanak, 2009). Reaksi tanah diukur dengan $\mathrm{pH}$ meter, sedangkan kadar air tanah ditetapkan secara gravimetri (Puslittanak, 2009). Analisis pH tanah dilakukan dengan menggunakan $\mathrm{pH}$ meter dengan perbandingan tanah dan air $1: 2,5$.

Data yang diperoleh dianalisis dengan analysis of varians dilanjutkan dengan uji BNT pada taraf 5\%. Analisis data dilakukan menggunakan perangkat lunak pengolah data SPSS seri 23.0 (IBM Inc. 23 ). Data yang dihasilkan ditampilkan dalam bentuk grafik garis kontinu menggunakan program Excel (Ms. Excel 2007).

\section{HASIL DAN PEMBAHASAN}

Hasil penelitian menunjukkan bahwa nilai $\mathrm{pH}$ tanah tidak berubah selama fase pertumbuhan padi sawah varietas lokal maupun hibrida (Tabel 1). Reaksi tanah juga tidak berubah setelah aplikasi pupuk urea pada fase pertama (20 HST) maupun fase ke 2 (50 HST).

Tabel 1. Kadar pH Tanah pada Padi Lokal dan Padi Hibrida

\begin{tabular}{ccc}
\hline Umur & $\begin{array}{c}\text { pH padi } \\
\text { Lokal }\end{array}$ & $\begin{array}{c}\text { pH padi } \\
\text { Hibrida }\end{array}$ \\
\hline OT & 6,58 & 6,54 \\
0 & - & 6,45 \\
7 & 6,38 & - \\
14 & 6,34 & 6,55 \\
21 & 6,48 & - \\
28 & 6,53 & 6,57 \\
42 & 6,38 & 6,54 \\
56 & 6,51 & 6,11 \\
70 & 6,1 & 6,57 \\
84 & 6,5 & 6,32 \\
98 & 6,38 & 6,53 \\
112 & 6,58 & 6,38 \\
126 & 6,37 & 6,02 \\
\hline
\end{tabular}


Nilai pH awal tanah sawah (Tabel 1) tergolong agak asam (6,58 dan 6,54). Memasuki umur 14 HST nilai $\mathrm{pH}$ pada tanah padi lokal yaitu 6,34 dan pada padi hibrida yaitu 6,56. Nilai tersebut mengalami kenaikan setelah pengaplikasian pupuk urea pada umur 20 HST menjadi 6,48 pada padi lokal dan 6,56 pada padi hibrida. Setelah pengaplikasian pupuk yang kedua yaitu pada umur $50 \mathrm{HST}$, nilai $\mathrm{pH}$ tanah hibrida mengalami penurunan menjadi 6,11 , sedangkan $\mathrm{pH}$ padi lokal naik menjadi 6,51. Kenaikan dan penurunan tersebut disebabkan oleh pemberian pupuk urea. Umumnya pemberian pupuk urea ke dalam tanah dapat menurunkan $\mathrm{pH}$ tanah. Pupuk urea yang semula kering, setelah menyerap air akan meningkat kadar airnya dan volumenya bertambah serta terjadi reaksi dengan air yang membebaskan ion hidrogen. Ion hidrogen yang terbebaskan tersebut berpengaruh terhadap peningkatan asam basa tanah.

Namun, pada penelitian ini tidak terjadi penurunan $\mathrm{pH}$ setelah pengaplikasian urea, hal tersebut dapat dipengaruhi oleh penggenangan yang dilakukan selama proses budidaya. Menurut ( Rachmawati, D. dan Retnaningrum, E. 2013) penggenangan akan menyebabkan perubahan $\mathrm{pH}$ tanah ke arah netral.

\section{Dinamika Amonium $\left(\mathrm{NH}_{4}^{+}\right)$dan} Nitrat $\left(\mathrm{NO}_{3}^{-}\right)$

Kadar amonium dan nitrat padi lokal (Gambar 1.) pada masa olah tanah (OT) memiliki tinggi yang sama yaitu 2,67\%, pada masa olah tanah tidak ada penambahan pupuk hanya pembenaman jerami padi dan tidak ada serapan hara $\mathrm{N}$ oleh tanaman sehingga proses yang terjadi adalah mineralisasi jerami dalam kondisi anaerob sehingga kadar amonium dan nitrat tinggi. 
GITA YUNI PERMATASARI. et al. Dinamika Amonium dan Nitrat Lahan Sawah Latosol...
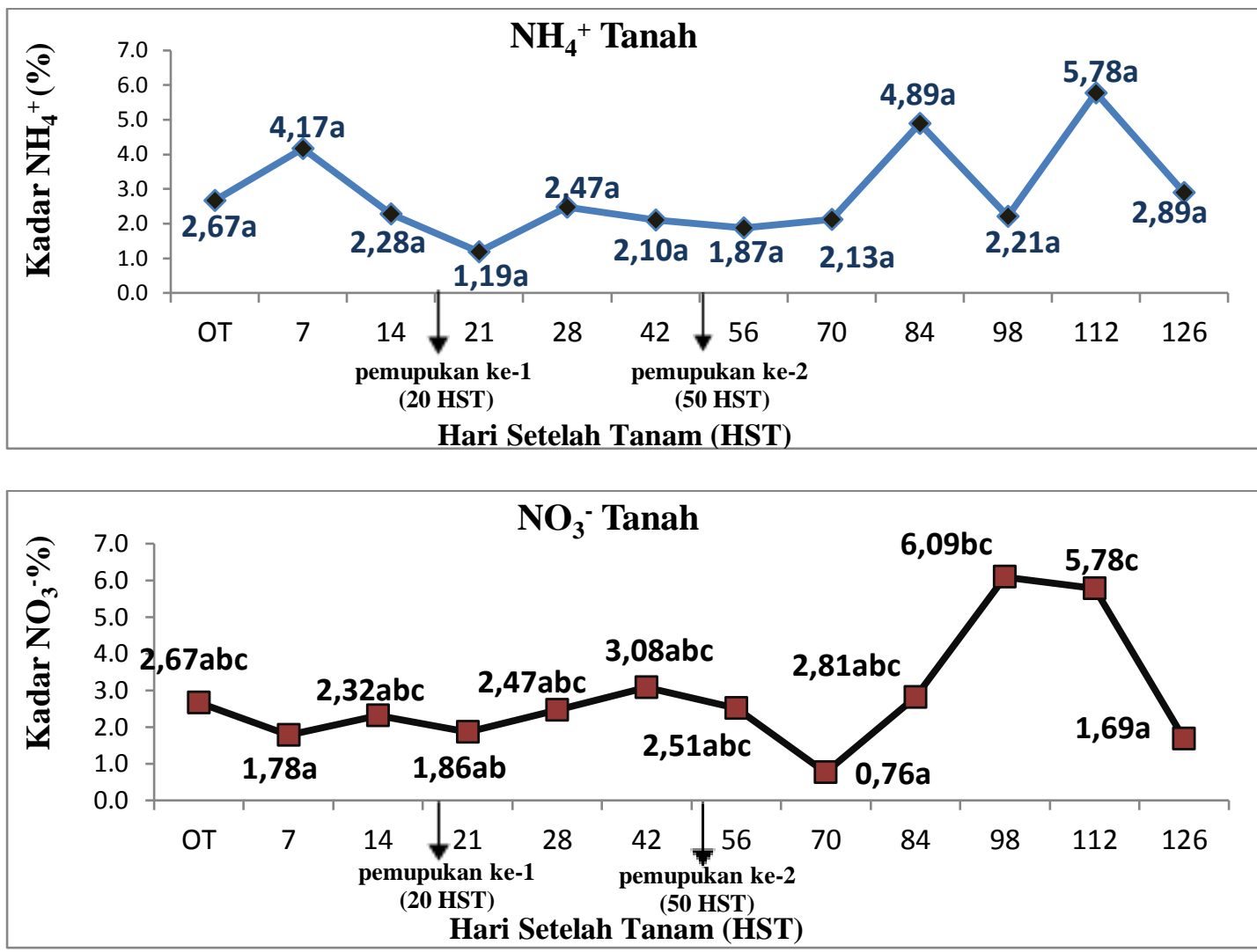

Gambar 1. Kadar Amonium $\left(\mathrm{NH}_{4}{ }^{+}\right)$dan Kadar Nitrat $\left(\mathrm{NO}_{3}{ }^{-}\right)$Tanah Padi Lokal

Umur 21 HST kedua parameter mengalami penurunan meskipun pada umur 20 HST dilakukan pemberian pupuk urea. Rendahnya kadar amonium dan nitrat pada umur 21 HST sesuai dengan penelitian yang telah dilakukan oleh Sholikah dkk., (2013) yang menyatakan bahwa kecepatan urea untuk dapat terhidrolisis tergantung pada kondisi tanah. Akan tetapi pada umumnya urea mulai dapat terhidrolisis pada hari ke-5 setelah pengaplikasian.

Memasuki umur 28 HST kadar amonium dan nitrat kembali naik karena diduga urea telah mengalami hidrolisis dengan baik sesuai dengan pendapat Sholikah dkk., (2013). Memasuki umur 42 HST hingga 56 HST proses nitrifikasi masih terus berjalan, hal tersebut ditunjukkan dengan meningkatnya kadar nitrat tanpa diikuti dengan naiknya amonium.

Memasuki umur 126 HST kadar amonium dan nitrat mengalami penurunan menjadi $2,89 \%$ amonium dan $1,69 \%$ nitrat. Turunnya kadar amonium dan nitrat pada umur tersebut diduga disebabkan kadar 
amonium dan nitrat dalam tanah sebagian besar telah diserap oleh tanaman.

Hasil analisis statistika menunjukkan bahwa pada kadar amonium air $\left(\mathrm{NH}_{4}{ }^{+}\right)$dan kadar nitrat air $\left(\mathrm{NO}_{3}{ }^{-}\right)$berbeda tidak nyata pada masing-masing umur tanaman
0\% terdapat pada umur $21 \mathrm{HST}$, sedangkan tertinggi yaitu $0,47 \%$ terdapat pada masa olah tanah. Kadar nitrat terendah yaitu $0 \%$ terdapat pada umur 21 HST, sedangkan tertinggi yaitu $0,37 \%$ terdapat pada umur 70 HST.

(Gambar 2.). Kadar amonium terendah yaitu
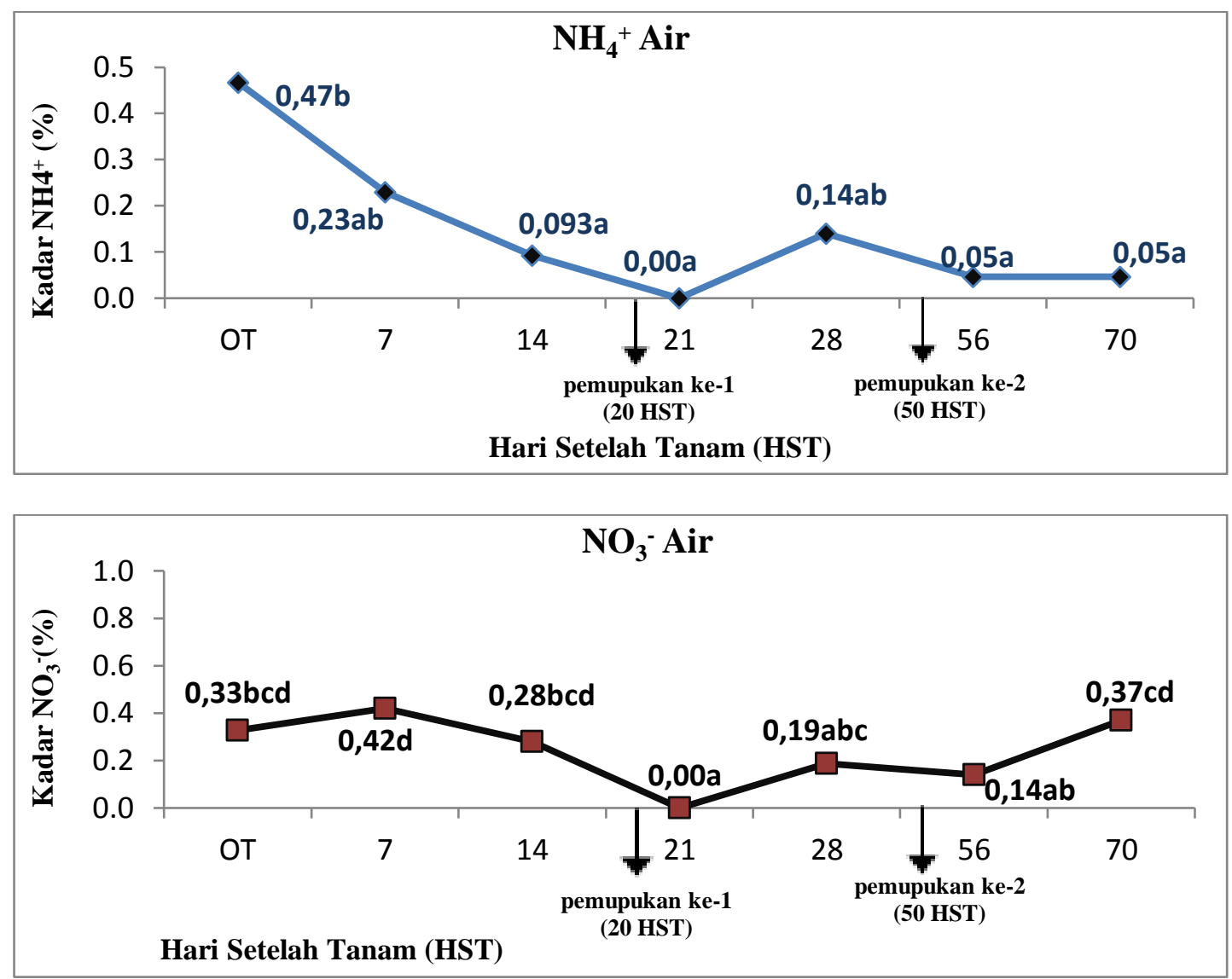

Gambar 2. Kadar Amonium $\left(\mathrm{NH}_{4}^{+}\right)$dan Nitrat $\left(\mathrm{NO}_{3}{ }^{-}\right)$pada Air Padi Lokal 
GITA YUNI PERMATASARI. et al. Dinamika Amonium dan Nitrat Lahan Sawah Latosol...

Kadar amonium dan nitrat tanah padi hibrida (Gambar 3.) pada masa olah tanah (OT) memiliki tinggi yang hampir sama yaitu amonium $1,72 \%$ dan nitrat $1,48 \%$. Selama masa olah tanah tidak dilakukan pemupukan, hanya saja dilakukan perendaman jerami yang memungkinkan terjadinya mineralisasi jerami. Awal tanam yaitu pada umur 0 HST kedua parameter kembali mengalami penurunan menjadi $0,99 \%$ amonium dan $0,76 \%$ nitrat, selanjutnya nitrat naik pada umur 14 HST menjadi 4,59\% sedangkan amonium tetap turun menjadi $0,96 \%$. Kenaikan nitrat pada umur 14 HST menunjukkan bahwa terjadi proses nitrifikasi pada umur tersebut.
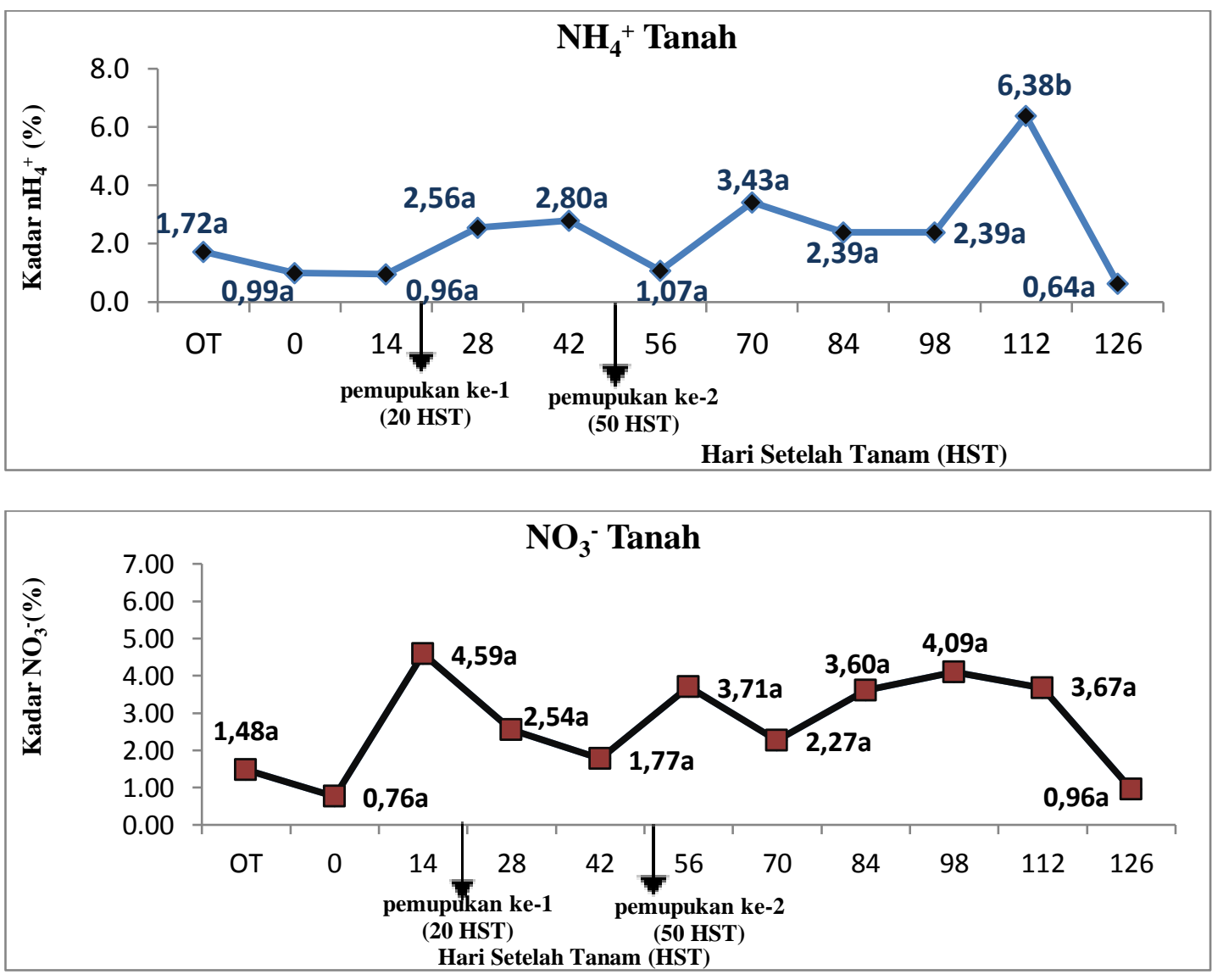

Gambar 3. Kadar Amonium $\left(\mathrm{NH}_{4}{ }^{+}\right)$dan Nitrat $\left(\mathrm{NO}_{3}{ }^{-}\right)$Tanah Padi Hibrida

Memasuki umur 28 HST amonium naik menjadi $2,56 \%$ hingga umur 42 HST menjadi 2,80\% sedangkan nitrat turun menjadi 2,54 pada umur 28 HST dan 1,77 
pada umur 42 HST. Turunnya nitrat pada umur 28 HST dan 42 HST dapat disebabkan nitrat telah diserap oleh tanaman atau mengalami denitrifikasi dikarenakan sifat nitrat yang mudah bergerak ke lapisan dalam tanah yang anaerob. Kadar amonium turun menjadi $1,07 \%$ dan nitrat naik menjadi $3,71 \%$ pada umur 56 HST. Rendahnya kadar amonium pada umur 56 HST dapat disebabkan tanaman telah memasuki masa primordia yang menyebabkan tanaman akan lebih banyak menyerap unsur hara tanah. Menurut Puji wibowo (2010) padi hibrida memasuki masa primordia pada umur 50 HST.

Kadar amonium kembali mengalami kenaikan pada umur 70 HST menjadi 3,43\% dan nitrat turun menjadi $2,27 \%$, selanjutnya nitrat mengalami kenaikan pada umur 84 HST (2,27\%) hingga umur 98 HST (4,09\%), sedangkan amonium memiliki tinggi yang sama pada umur 84 HST dan 98 HST yaitu 2,39\%. Memasuki umur 112 HST amonium naik menjadi 6,39\% dan nitrat turun menjadi $3,67 \%$. Kedua parameter mengalami penurunan pada umur 126 HST menjadi 0,64\% kadar amonium dan
0,96\% kadar nitrat. Rendahnya kadar amonium dan nitrat pada umur 126 disebabkan oleh tanaman telah dipanen sehingga unsur hara telah diserap oleh tanaman.

Hasil analisis statistika menunjukkan bahwa pada kadar amonium air $\left(\mathrm{NH}_{4}{ }^{+}\right)$ terdapat berbeda nyata pada umur 14 HST yaitu 0,33 c. Kadar nitrat air $\left(\mathrm{NO}_{3}{ }^{-}\right)$pada umur 42 HST yaitu $0,47 \mathrm{~d}$ berbeda nyata dengan masa olah tanah (OT), umur 0, 14 dan 56 HST (Gambar 4). 
GITA YUNI PERMATASARI. et al. Dinamika Amonium dan Nitrat Lahan Sawah Latosol...
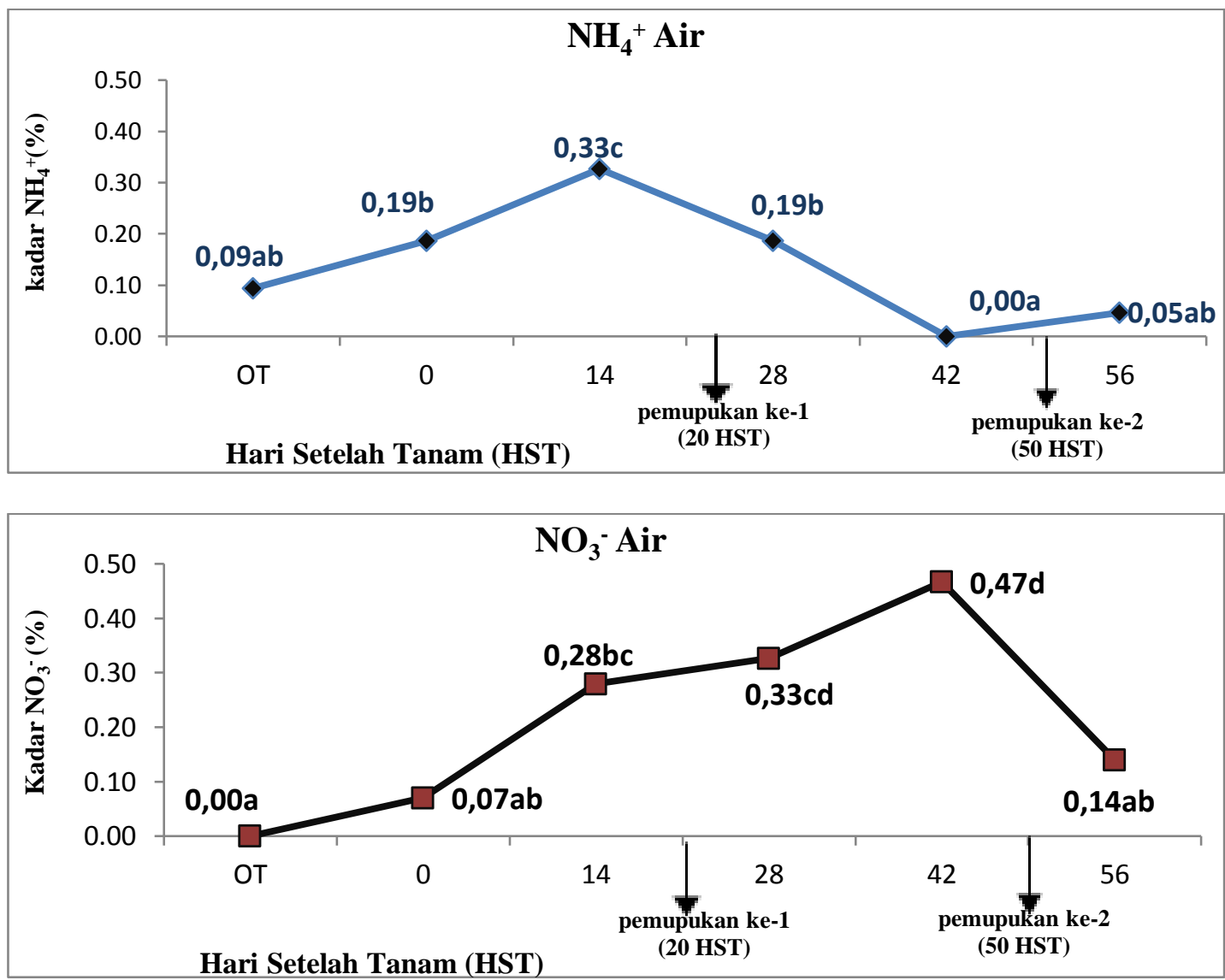

Gambar 4. Kadar Amonium $\left(\mathrm{NH}_{4}{ }^{+}\right)$dan Nitrat $\left(\mathrm{NO}_{3}{ }^{-}\right)$pada Air Padi Hibrida

\section{Waktu Pemberian Pupuk Susulan}

Hasil penelitian menunjukkan bahwa kadar $\mathrm{NH}_{4}{ }^{+}$dan $\mathrm{NO}_{3}{ }^{-}$menurun pada umur 21 HST dan umur 56 HST. Melihat dari penurunan tersebut kedua jenis padi tidak memiliki perbedaan waktu pemupukan pertama. Hanya saja, padi lokal dan hibrida memasuki masa primordia pada umur yang berbeda, hal tersebut menyebabkan keduanya memiliki waktu pemupukan susulan yang berbeda. Pemupukan susulan yang direkomendasikan yaitu 60-65 HST pada padi lokal dan 40-45 pada padi hibrida.

\section{SIMPULAN}

Dinamika amonium $\left(\mathrm{NH}_{4}{ }^{+}\right)$dan nitrat $\left(\mathrm{NO}_{3}{ }^{-}\right)$tanah padi lokal dan padi hibrida memiliki fluktuasi yang hampir sama. Setelah 1 hari setelah pengaplikasian pupuk yaitu pada umur 21 HST kadar amonium dan nitrat pada padi lokal menurun namun pada umur 28 HST kadar amonium dan nitrat pada kedua jenis padi meningkat. Menginjak umur 
56 HST kadar amonium pada padi lokal dan hibrida menurun.

Jadwal pemupukan susulan seharusnya berbeda untuk padi lokal dan hibrida. Waktu pemupukan yang direkomendasikan yaitu umur 10-15 HST untuk pemupukan pertama pada kedua jenis padi sedangkan pemupukan kedua pada padi lokal umur 60-65 HST dan 40-45 HST pada padi hibrida.

\section{DAFTAR PUSTAKA}

Balai Penelitian Tanah. 2009. Analisis Kimia Tanah, Tanaman Air, dan Pupuk (Edisi 2). Bogor

Balai Penelitian Tanah. 2011. Analisis Komparatif Sistem Pertanian Konvensional, PTT dan SRI di Lahan Sawah Irigasi Jawa Barat terhadap Keseimbangan Hara, Dinamika Biologi, Efisiensi Pupuk dan Nilai Ekonomi Usahatani. Bogor

Haryatie . 2013. Alasan Petani dalam Mengambil Keputusan Menanam Suatu Jenis Varietas Padi.

Ladiyani R.W., D. Nursyamsi, S.Rochayati \& M. Sarwani. 2011. Nitrogen Management on Agricultural Land in Indonesia. Agricultural N Emissions. Taipe, Taiwan.

Patti, P.S. Kaya \& Ch. Silahooy. Analisis Status Nitrogen Tanah dalam Kaitannya dengan Sera[an N oleh Tanaman Padi Sawah di Desa Waimital, Kecamatan Kairatu, Kabupaten Seram Bagian Barat. Ambon

Puji, W. 2010. Pertumbuhan dan Produktivitas Galur Harapan Padi (Oryza Sativa. L) Hibrida di Desa
Ketaon Kecamatan Banyudono Boyolali. Semarang.

Rachmawati D., \& Retnaningrum E. 2013. Pengaruh Tinggi dan Lama Penggenangan Terhadap Pertumbuhan Kultivar Sintanur dan Dinamika Populasi Rhizobakteri Pemfiksasi Nitrogen Non Simbiosis. Yogyakarta.

Sholikah, M.H., Suyono, \& Wikandari P.R. 2013. Efektivitas Kandungan Unsur Hara N Pada Pupuk Kandang Hasil Fermentasi Kotoran Ayam Terhadap Pertumbuhan Tanaman Terung (Solanum Melongena L.). Journal of Chemistry,. 2(1):131

Suwastika, A.A.N.G., N.N. Soniari \&A.A.I. Kesumadewi. 2018. Biologi Tanah. Prodi Agroekoteknologi Fakultas Pertanian Universitas Udayana, Denpasar. 